IRA-International Journal of Education \& Multidisciplinary Studies

ISSN 2455-2526; Vol.11, Issue 03 (June, 2018)

Pg. no. 49-62.

Institute of Research Advances

http://research-advances.org/index.php/IJEMS

\title{
Antecedents of Children of Alcohol Abused Parents: Grounded Theory Analysis
}

\author{
Abijo Temitayo Serah ${ }^{1 \#}$, Huzili Hussin ${ }^{2}$, Hanif Suhairi ${ }^{3}$ \\ ${ }^{1}$ Dept of Education and Sport Science, Universiti Malaysia Perlis, Malaysia. \\ ${ }^{2,3}$ School of Human Development and Technocommunication (IKOM), Universiti Malaysia Perlis, \\ Malaysia.
}

\#corresponding author.

Type of Review: Peer Reviewed.

DOI: http://dx.doi.org/10.21013/jems.v11.n3.p1

How to cite this paper:
Serah, A. T., Hussin, H., Suhairi, H. (2018). Antecedents of Children of Alcohol Abused Parents:
Grounded Theory Analysis. IRA International Journal of Education and Multidisciplinary Studies (ISSN
2455-2526), 11(3), 49-62.doi: http://dx.doi.org/10.21013/jems.v11.n3.p1

(C) Institute of Research Advances.

\section{(cc) EY-NC}

This work is licensed under a Creative Commons Attribution-Non Commercial 4.0 International License subject to proper citation to the publication source of the work.

Disclaimer: The scholarly papers as reviewed and published by the Institute of Research Advances (IRA) are the views and opinions of their respective authors and are not the views or opinions of the IRA. The IRA disclaims of any harm or loss caused due to the published content to any party.

Institute of Research Advances is an institutional publisher member of Publishers Inter Linking Association Inc. (PILA-CrossRef), USA. The institute is an institutional signatory to the Budapest Open Access Initiative, Hungary advocating the open access of scientific and scholarly knowledge. The Institute is a registered content provider under Open Access Initiative Protocol for Metadata Harvesting (OAI-PMH).

The journal is indexed \& included in WorldCat Discovery Service (USA), CrossRef Metadata Search (USA), WorldCat (USA), OCLC (USA), Open J-Gate (India), EZB (Germany) Scilit (Switzerland), Airiti (China), Bielefeld Academic Search Engine (BASE) of Bielefeld University, Germany, PKP Index of Simon Fraser University, Canada. 


\begin{abstract}
This research endeavored to fill the knowledge gap in children of alcohol abuse parents by uncovering one of the five fundamental themes of children of alcohol abuse parent, that is, the antecedents that add to the working hypothesis or paradigm model of the phenomenon. In-depth interviews were conducted with 19 children and seven parents who were recruited through Alcohol Abuse and Family Support Agency. A Grounded Theory approach was adopted to analyze the transcribed interview data. Nvivo 10 software was used in analyzing the data by methodologically coding and categorizing the data in open, axial and selective coding. Five major themes emerged from the analysis, which is referred to as antecedents of parents' alcohol abuse phenomenon, Description of alcohol abuse phenomenon, Contexts and prevailing conditions affecting alcohol abuse, coping strategies and consequences of alcohol abuse on children. Based on this, the study was set out to construct a grounded theory of the phenomena of children in the alcohol abused families in Nigeria rooted in the description of their own comprehensive experience. This study is planned to benefit all parties: parents, teachers, counselors and other stakeholders to minimize the effect of parent alcohol abuse on children.
\end{abstract}

Keywords: Alcohol abuse, antecedents, grounded theory, children, Environmental problem.

\title{
Introduction
}

Alcohol abuse and related illicit activity remain serious problems that affect the lives of most Nigerians therefore; the necessity for in-depth research becomes imperative. Alcohol abuse, [6] is the wrong use or unseemly use of biochemical alcohols that are able to change the functions of cells in the body. The abuse of alcohols, particularly within the family, has become a real social threat which cut across all part of Nigeria with children bearing the brunt mostly [14]. Based on the statistics of alcohol abuse in Nigeria, the Northwest has 37.47 percent of the alcohol abusers in the country, whereas the Southwest is ranked second with 17.32 percent. The south-East has been ranked third with 13.5 percent, while the North-central is 11.71 percent, and the North-east zone is rated 8.54 percent of the alcohol users in Nigeria [3, 22]. However, in each of these zones, the devastating effects on the families are continuing to be receiving less attention [22]. In view of this therefore, this current study will explore the personal experiences and perceptions of children in a alcohol abused family in the context of Nigeria. Therefore, alcohol, according to mental health experts, is a catalyst for crime, as most criminal acts are committed under the influence of alcohols [27].

\section{Current study}

Alcohol abuse has all along directed attention at the outcome of school, street and work place and problem of alcohol abuse at other levels are usually not traced directly to their families. Currently, alcohol abuse has been directly traced to the family which influences the children and other relations.

\section{Problem statement}

Alcohol abuse remains a general health challenge and a social issue of colossal sizes with numerous adolescents and families included and influenced by alcohol abuse disorders [6, 11, 33]. Predominantly, family alcohol abused prevalence is growing considerably higher, with estimates suggesting that up to $30 \%$ of families include at least one alcohol or alcohol-abusing member and that not as much as half (44\%) of children destined to alcohol abusing moms lived with original parent and $20 \%$ were in custodian care or set outside of the family $[11,43]$.

Presently, alcohol abuse is one of the monster threatening family structures. As indicated by [15] the spate of alcohol abuse in families in Nigeria has achieved disturbing point in light of the fact that at present, just few is free of alcohol abuse and unfortunately, nothing is being done about it. Similarly, in Nigeria, the circumstance appears there is a high pervasiveness of alcohol use particularly among family members and there is high probability that the recurrence will keep on increasing [6].

Also, and most essentially, because children commonly are highly attached to their parents, the affection relationship might reinforce the impact of family alcohol abused on the children. For instance, according to [31] children are expected to behave in a manner that is not age- appropriate. Likewise, children of alcohol abused families may experience feelings of neglect, anxiety, fear, anger. More so, children are confused because they cannot figure out the limitations of right and wrong. As a result, the problem translates to cognitive, behavioral, psychosocial, and emotional consequences for children [41]. Most welfare experts (79.6\%) report that alcohol abuse causes or adds to at any rate half of all cases of child abuse; $39.7 \%$ say it is a factor in more $75 \%$ of the cases [30]. 
Corroborating this, [1] the issue of alcohol abuse needs pressing responsiveness because of the startling rate and more so, that children of these families who are innocently in danger gets less consideration. According to [26] alcohol abuse can significantly affects the health of children who are either exposed to nicotine, alcohol or illegal alcohols through parental alcohol abuse or experience childhood in an alcohol abusing family. Similarly, [18] believed that the broad pervasiveness of illegal alcohol use which is high within the family introduces another sign of the requirement for continued research on the grounds that it is a hazard factor for children.

According to [42] the climate conditions in the home have a great impact either negatively or positively on the character of the children in that home, therefore, families could be said to be the strongest socializing forces of life. In alcohol free families, as noted by [33] children are educated to shun undesirable behaviors, however on the contrary, in alcohol abused families, children can learn aggressive, antisocial and violent behaviors as well. That is why scholars $[12,17,39]$ concluded that it could be rightly presumed that the behavioral patterns young person came up with could be traced to their home background. In that light also, [39] stressed that alcohol abused related family failure to adequately parent children places a tri-generational burden on society. In spite of this huge implication, there remains a disconnect between what is now known methodically about alcohol abuse and the public's understanding of and beliefs about abuse within the families and the magnitude to which what is known is in reality applied in public health situations and society at large [17, 26]. Similarly, while governments are preoccupied at expanding their economic development and consequently focusing the greater part of their resources towards that path, incidentally, alcohol and alcohol abuse threatens to dissolve those gains.

Reiterating the challenges surrounding the phenomena, [29] recounted that, in spite of the wide-reaching concern as well as education about alcohol abuse, many families and adolescents have shown partial sensitivity to the adverse consequences on the children and society in general. More so, according to [22], [2], [4], 9\% to 10\% of the national budgetary allocation for health is being consumed for treatment and rehabilitation of those with alcohol abuse problems in Nigeria. Similarly, attention is required because in Nigeria the children of alcohol abused families have mainly stayed hidden from view and rehabilitation. The damage done to them is typically also not traced directly to their families; consequently, the right strategies to handle the menace could not be identified.

In relation to this, the children of alcohol abused families are prone to the risk of misusing alcohols themselves thereby sustaining the cycle of abuse [5, 40]. In view of this therefore, the absence of regard for the necessities of children of alcohol users suggest that at a key level, neither the number of children involved nor the degree of their needs has yet been completely perceived [7]. Similarly, [27] has indicated that less attention has been given to children of families in alcohol abuse, in spite of the fact that alcohol is associated with 33\% of child abuse cases and $40 \%$ of aggressive behavior at home incidences. Also, [36] disclosed that in UK, in spite of the fact that there are between 780,000 and 1.3 million children who are influenced by parent alcohol problems, the children are not given required attention. As noted by [6] due to the stark effects linked with alcoholism in Nigeria as explained above then a knowledge gap exists regarding the effects on the children of alcohol abused families.

\section{Methodology}

\section{Participants}

A total of 19 children of alcohol abusing parents whose age ranges between 10 and 21 years and seven (7) parents who abused alcohol participated in this study. Data were collected over a period of three months. These periods were selected because these are the periods that majority of the children are mostly home being holiday time in Nigeria. It is believed that these periods are when the children experience mostly the challenges of families' alcohol abuse. Most of the informants were recruited through Non-GovernmentalOrganization (NGO) in the South West, Nigeria and other participants were picked through snow-balling technique as the children inform about others whose parents engage in alcohol abuse activities.

\section{Procedure}

Data were collected using grounded theory procedures described in [37, 38]. Reference [9] suggested that a standard grounded theory research will comprise 20 to 30 interviews that collectively saturate the categories that emerge during analysis. Data are accumulated in four phases that differ with regard to purpose and data collection strategies [14] are summarized in Table 1. Analysis of data of current study were completed by using NVivo Version 10 Software as to meet the terms of "trustworthiness", "rigorousness", or "quality" of the data, therefore it is important 
that this are carried out in a thorough and transparent manner $[8,9,19,20,25 \& 35]$. Therefore, using software in the data analysis process has been agreed to add rigor to qualitative research [32].

Table 1: Four phase of data collection

\begin{tabular}{|c|c|c|}
\hline Phase & Coding & Purpose \\
\hline 1 & Open & Categorizes codes within categories for advance analysis \\
\hline 2 & Axial & Specifies codes in detail; relay codes to one another to create themes \\
\hline 3 & Selective & $\begin{array}{l}\text { Creates paradigm model and discuss themes in relative to model; } \\
\text { Establish plan that incorporates paradigm model }\end{array}$ \\
\hline 4 & Selective & $\begin{array}{l}\text { Test, certify and explain paradigm model until saturated; } \\
\text { recognize surfacing principles constant with paradigm model; perform } \\
\text { member checks. }\end{array}$ \\
\hline
\end{tabular}

The Phase 1 is open coding in the data analysis of a grounded theory. In open coding, the researcher forms initial five categories of information (antecedents of the alcohol abuse families, description of alcohol abuse, context and conditions that affect the children in alcohol abuse families, coping strategies, and consequences of alcohol abuse families' phenomenon) being studied, in this case, the children in alcohol abuse families, by segmenting the information [39]. The main purpose of open coding is to differentiate significant topics of closer analysis and explanation [38]. All interviews are based on open ended responses to the following questions:

Interview questions for the children

1. How would you describe your parent alcohol abuse situation?

2. How do you spend most of your time?

3. How does your parent spend their time?

4. How does your parent alcohol abuse affect the home?

5. What are the factors influencing your parent alcohol abuse?

Interview questions for parents

1. How would you describe your alcohol abuse situation?

2. How do you spend most of your time?

3. How does your alcohol abuse affect the home?

4. What are the factors influencing your alcohol abuse?

These questions are consistent to the major elements of the paradigm model described by [38]. Table 2 shows preliminary codes obtained from the interview sessions with each code represent a significant topic of discussion related to parents' alcohol abuse. Many children for instance, mentioned that economic problem is a factor influencing their parents' alcohol abuse. The researcher thus concluded that individual interviews saturated the codes that were necessary to understand the phenomenon of children of alcohol abusing families after similar codes emerged during the interviews. In Phase 2 which is axial coding, the categories generated in open coding are positioned within the theoretical model. The phase used clusters codes into themes and patterns related to a central phenomenon (the children in alcohol abuse families). Therefore, Phase 2 data collection has allowed the researcher to construct a better understanding of each of the five main components in the paradigm model [38]. After a question had been addressed, the researcher probed specific categories that emerged during the analysis in Phase 1.

Furthermore, the researcher has identified a variety of initial themes on the basis of the five categories and codes then combined themes in a manner consistent with the interviews. Structured interviews were used in which each individual (children and parent) responded to the follow up questions and probes. Question 1 intended to explain a typical parental alcohol abuse situation while other questions were based on the questions presented in Phase 1 of data collection. Follow-up probe questions were included to focus in details on prominent categories mentioned during Phase 1.

The researcher identified a variety of initial themes on the basis of the five categories and codes then combined themes in a manner consistent with the interviews. It is important to note that Phase 2 provided the researcher with the opportunity to organize and label themes that could be tested in Phase 3. Therefore, macro-themes and themes identified in Phase 2 were viewed as tentative in nature, subject to revision or deletion in Phase 3. 
In Phase 3 which is the selective coding, the researcher finally clarified categories into a storyline based on the interconnections of these categories $[10,38]$. Through this process the theory development was displayed as the more concrete aspects of the children in alcohol abuse families are refined and integrated into more theoretical and abstract ideas. Informants were interviewed using the in-depth interview from Phase 2 with several additional probes in each question which asked informants to elaborate on themes identified in Phase 2. These interviews served to reproduce vital codes and themes that were identified in Phases 1 and 2.

Table 2: Initial categories and codes

\begin{tabular}{|c|c|}
\hline Category & Codes \\
\hline \multirow[t]{18}{*}{ Antecedents } & 1. Confused and insecure \\
\hline & 2. Marital Discord \\
\hline & 3. Mistrust \\
\hline & 4. Economic challenge \\
\hline & 5. Environmental problem \\
\hline & 6. Spouse infidelity \\
\hline & 7. Job loss \\
\hline & 8. Promotion retardation \\
\hline & 9. Business challenge \\
\hline & 10. Business failure \\
\hline & 11. Debts \\
\hline & 12. Inspiration \\
\hline & 13. Easy access \\
\hline & 14. Reliance on friends \\
\hline & 15. Boredom \\
\hline & 16. Belongingness \\
\hline & 17. Self-esteem \\
\hline & 18. Socio-economic status \\
\hline \multirow[t]{12}{*}{ Description of alcohol abuse phenomenon } & 19. Stimulate fighting \\
\hline & 20. Prompt nagging \\
\hline & 21. Complain \\
\hline & 22. Opportunist drinking \\
\hline & 23. Influence physical altercations \\
\hline & 24. Influence disorderly \\
\hline & 25. Conduct in public \\
\hline & 26. Addictive substance \\
\hline & 27. Coercive relationship \\
\hline & 28. To catch fun \\
\hline & 29. To free from boredom \\
\hline & 30. To escape spouse nagging \\
\hline \multirow[t]{9}{*}{ Context and prevailing conditions } & 31. Emotional hitches \\
\hline & 32. Physical hitches \\
\hline & 33. Mental health problems \\
\hline & 34. External abuse \\
\hline & 35. Decreased social adequacy \\
\hline & 36. Hot temperament \\
\hline & 37. Withdrawn \\
\hline & 38. Decreased family cohesion \\
\hline & 39. Increased family isolation \\
\hline
\end{tabular}


40. Lack of control

41. Poor parent-child interactions

\section{Coping strategies}

Consequences
42. Resiliency

43. Autonomy

44. Forming bonds

45. Secure attachment pattern

46. Showing love

47. Stronger social skills

48. Self-efficacy

49. School friendships

50. Hypervigilant

51. Social adjustment

52. Self-regulation

53. Less warmth

54. Reliance on stepparent, grandparent, teachers

55. Social exclusion

56. Feelings of abandonment

57. Seclusion

58. Emotional isolation

59. Avoidance

60. Keeping watch

61. Externalization

62. Internalization

63. Protective factors

64. Higher levels of internalizing

65. Cognitive deficits

66. Lower self-esteem

67. Depression

68. Anxiety

69. Stress related problem

70. Less effective discipline

71. Impaired learning capacity

72. Attention deficit hyperactivity disorder

73. Skip class

74. Scholl absenteeism

75. Sponsorship challenge

76. Assume parent roles

77. Increased rates of anxiety

78. Social competence deficits

79. Intolerance

80. Avoidance of intimacy

81. Overly critical

82. Less warmth

83. Emotional isolation

84. Less parental monitoring

85. Separation anxiety

86. Sense of not being loved

87. Feelings of low self-worth

88. Embarrassment

89. Guilt 
90. Adverse behavioural outcomes

91. Encountering stigma

92. Feeling anxious

93. Upset

94. Worried

95. Fearful

96. Sad

97. Angry

98. Frustrated

99. Physical abuse

100.Sexual abuse

101.Depression and abandonment

102.Parental inconsistency

103. Denial of problem

104.Miscarried expression of anger

105.Inappropriate sexual behavior

106.Isolation

A second purpose was to investigate the preliminary diagrams of the paradigm model and asked informants to comment on whether the model made sense to them as well as if it was consistent with their experience as children of alcohol abuse families. The third intention was to ask informants to refine or add to any of the categories, macro themes, or themes in the paradigm model. Also, to require informants to discuss how the five categories in the paradigm model related to each other. Based on this, it was common for informants to discuss the relationship between one category (contextual conditions) and a second category (coping strategies) in a manner that shed light on the alcohol abuse in the families. This information assisted the researcher construct a plausible paradigm model that could be validated in Phase 4. A final goal was to construct a storyline, which consists of a descriptive story about the children of alcohol abuse families.

Table 3: Macro-themes and Themes in Phase 3

\begin{tabular}{|c|c|c|}
\hline Category & Macro themes & Themes \\
\hline \multirow[t]{3}{*}{$\begin{array}{l}\text { Antecedents of parents alcohol } \\
\text { abuse phenomenon }\end{array}$} & Dysfunctiona families & $\begin{array}{ll}\text { 1. } & \text { Confused and insecure } \\
\text { 2. } & \text { Marital discord } \\
\text { 3. } & \text { Mistrust } \\
\text { 4. } & \text { Economic challenge } \\
\text { 5. } & \text { Environmental problem }\end{array}$ \\
\hline & Job challenge & $\begin{array}{ll}\text { 6. } & \text { Job loss } \\
\text { 7. } & \text { Promotion retardation } \\
\text { 8. } & \text { Business challenge }\end{array}$ \\
\hline & Peer influence & $\begin{array}{l}\text { 9. Reliance on friends } \\
\text { 10. Friends instigation } \\
\text { 11. Boredom }\end{array}$ \\
\hline $\begin{array}{l}\text { Description of alcohol abuse } \\
\text { phenomenon }\end{array}$ & Ridiculous behavior & $\begin{array}{l}\text { 12. Stimulate nagging and } \\
\text { fighting } \\
\text { 13. Influence disorderly }\end{array}$ \\
\hline
\end{tabular}




\section{Context and prevailing conditions affecting alcohol abuse}

\section{Coping strategies}

\section{Consequences of alcohol abuse} on children
Problem escapism

Depression and anxiety

Communication breakdown

Positive outcomes

Negative outcomes

Repercussion on children

Poorer academic outcomes

Poorer emotional wellbeing
14. Bad conduct in public

15. Addictive substance

16. Coercive relationship

17. To catch fun

18. To free from boredom

19. To escape spouse nagging

20. Mental health problems

21. Hot temperament

22. Withdrawn

23. Decreased family cohesion

24. Lack of control

25. Weak parent-child interactions

26. Resiliency

27. Autonomy

28. Forming bonds

29. Rehabilitation efforts

30. Spiritual efficacy

31. Self-efficacy

32. Social adjustment

33. Self-regulation

34. Seclusion

35. Emotional isolation

36. Avoidance

37. Keeping watch

38. Externalization

39. Internalization

40. Lower self-esteem

41. Stress related problem

42. Breakdown of discipline

43. Physical abuse

44. Impaired learning capacity

45. Attention deficit

46. School absenteeism

47. Sponsorship challenge

48. Assumes parent roles

49. Increased rate of anxiety

50. Social competence deficits

51. Feeling of guilt

52. Encountering stigma

53. Depression and abandonment 
54. Family disunited

55. Denial of problem

56. Overburden mother

57. Antisocial behavior

58. Unrealistic expectations

59. Constant domestic disputes

As a final point, Phase 4 was intended to verify and elucidate on the paradigm model constructed in Phase 3. Informants were asked to respond to a paradigm model based on responses in Phase 3 . This phase of data collection served to conduct member checks on the preliminary paradigm model. Though, it was difficult getting a considerable number of the children to participate in the member checking, as well as paying attention to the confirmatory exercise but few of the adolescents were eventually made to answer whether the themes and macrothemes were plausible to them.

The other intent for this phase was to solicit comments and reactions regarding the credibility of the paradigm model. Meanwhile, in line with the objective of the study, some of the parents were involved in the interview as informants. So, the Informants in Phase 4 were shown preliminary diagrams of the paradigm model and asked to comment on whether the model made sense to them and if it was consistent with their own experience as children of alcohol abuse families on one hand and if it covered their own behavior as alcohol abuser. A third purpose was to invite respondents to refine or add to any of the categories, macrothemes, or themes in the paradigm model. This concluding stage was meant to guarantee that the ultimate paradigm model attains saturation, reliability, as well as credibility [24]

\section{Adequacy of Current Research Procedure}

The issue of rigor and quality, both in terms of the procedure and the results have been stressed by [38, 21,16] Therefore, in order to obtain good results for this grounded theory, the current research followed [37] submission that researchers should detail out the information concerning the research process outlined as seven criteria and specific questions for judging the adequacy as in table 4.

\section{Table 4: Strauss \& Corbin's Research Process}

\begin{tabular}{|l|l|}
\hline Criterion number 1 & The selection of original sample and justification of using purposive sampling. \\
\hline Criterion number 2 & Core categories surfaced. \\
\hline Criterion number 3 & Events, occurrences, actions and so on that revealed some these major categories. \\
\hline Criterion number 4 & Depiction of how theoretical formulations affected or guided the collection of data. \\
\hline Criterion number 5 & $\begin{array}{l}\text { The elaboration with respect to the hypotheses and justifications for the establishment of } \\
\text { connections amongst categories and the method to validation. }\end{array}$ \\
\hline Criterion number 6 & The accounting for discrepancies in the data and resulting theoretical modifications. \\
\hline Criterion number 7 & The rationale for the selection of the main or core category. \\
\hline
\end{tabular}

In this way, the table gives the analytic choices that happened within the present study in subtle elements. The documentation of data collection and analysiswithin each of the stages show the rationale of the coding techniques. This systematic management of data in the research procedure additionally exhibits the dependability of the research[13].

\section{Results and interpretations}

Data analysis of informants $(n=26) \mathrm{CAAF}=19, \mathrm{P}=7)$ using NVivo 10 established that the four main principles of children alcohol abusing parents that were acknowledged in the literature review surfaced as the key concepts in this research. Beside antecedents, contexts and conditions or prevailing conditions, coping strategies and consequences, 
description of alcohol abuse also surfaced as significant conceptions. Figure 1 points out the main themes and subthemes that construct children alcohol abuse parent among informants.

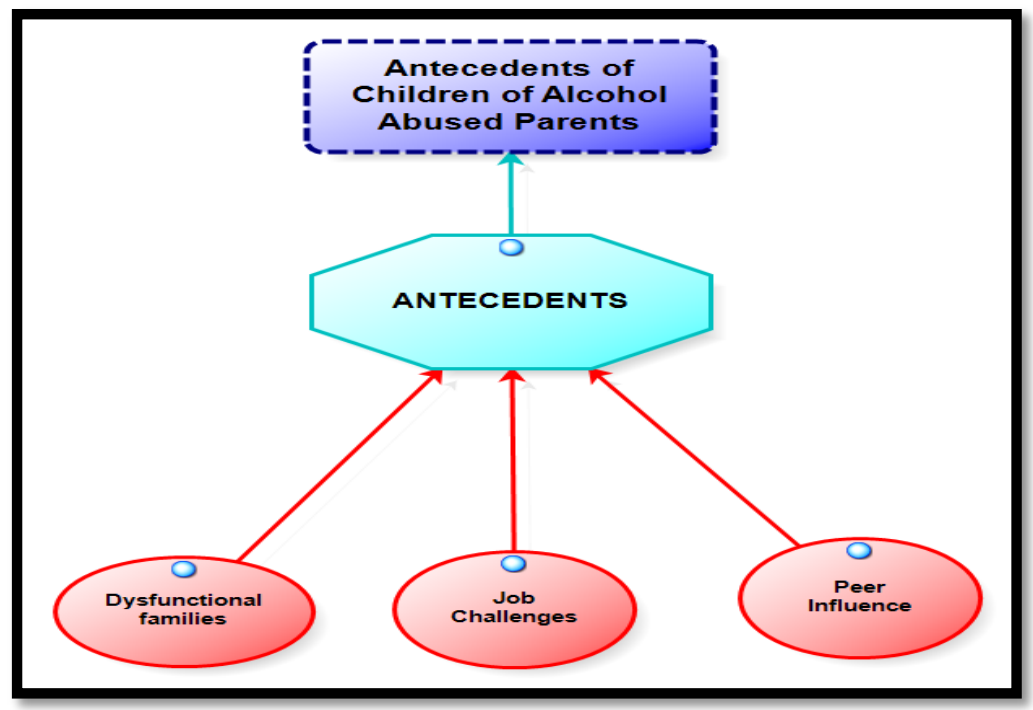

Figure 1: The main themes on antecedents of children of alcohol abuse parents

Children of alcohol abusing parent attributed their parent alcohol abuse to three types of antecedents including dysfunctional families, job challenges and peer influence as aiding factors to parental alcohol abuse and subsequently the phenomenon on the children as shown in figure 1.

\section{Dysfunctional Families}

The evidence from this study's interviews as indicated in figure 2 shows that significant number of interviewees was of the view that dysfunctional families play a role as the antecedent of alcohol abuse of parents. Their responses highlighted five specific ways through which dysfunctional families become the antecedent. On economic challenge as a factor motivating alcohol abuse, (CAAF 11.5\%, and P 3.8\%) agreed on this.

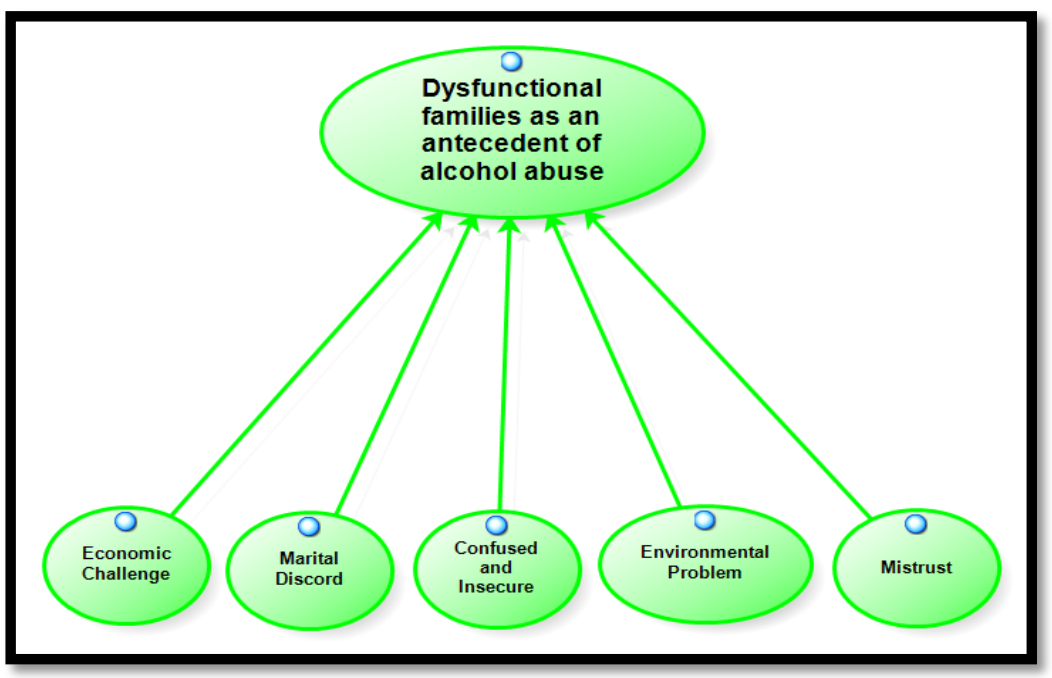

Figure 2: Dysfunctional Families as an Antecedent of Alcohol Abuse 
Also, it was revealed that some informants (CAAF 19.2\%) claimed that marital discord is an impetus for alcohol abuse of some of the parents. Similarly, based on the findings (CAAF 11.5\%), there is a claim that most of the parents got into alcohol abuse as a result of job insecurity which usually lead to confusion. The researcher found that many children of alcohol abusing families (CAAF 42.3\%) perceived that their parent alcohol abuse were being influenced by environmental problem while parents (P 3.8\%) disclosed this perception of abuse as environmental influence. Equally, informants (CAAF 15.4\%) claimed that mistrust led to their parents' alcohol abuse.

Job Challenges as Antecedent of Parental Alcohol Abuse

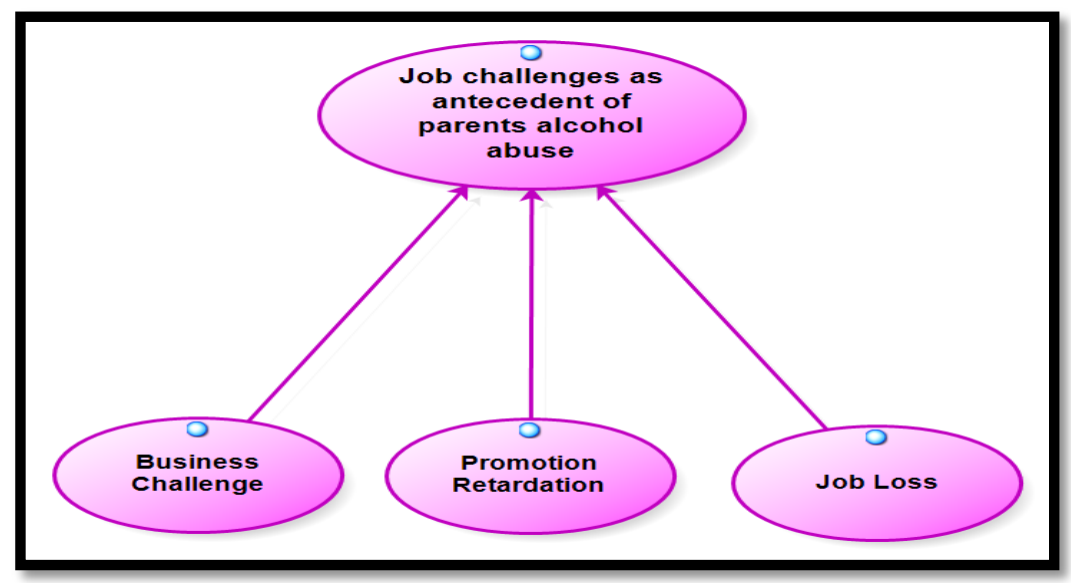

Figure 3: Job Challenges as Antecedent of Parental Alcohol Abuse

The findings as stated in Figure 3 revealed that job challenges play an important role as an antecedent of alcohol abuse in the families. The participant's perception emphasized three explicit means through which job challenge becomes an antecedent. Most of the respondents (CAAF 30.8\%) claimed that job loss was the reason for their parent's alcohol abuse which some parents (P 11.5\%) attested to. Also, the prompting behavior as a result of business challenge was described by the informants (CAAF 26.9\%). The perspective also emerged from this study finding as the informants (CAAF 3.8\%, P 3.8\%) attested that frustration due to promotion retardation sometimes work as the antecedent to alcohol abuse of parents.

\section{Peer Influence as an Antecedent of Parental Alcohol Abuse}

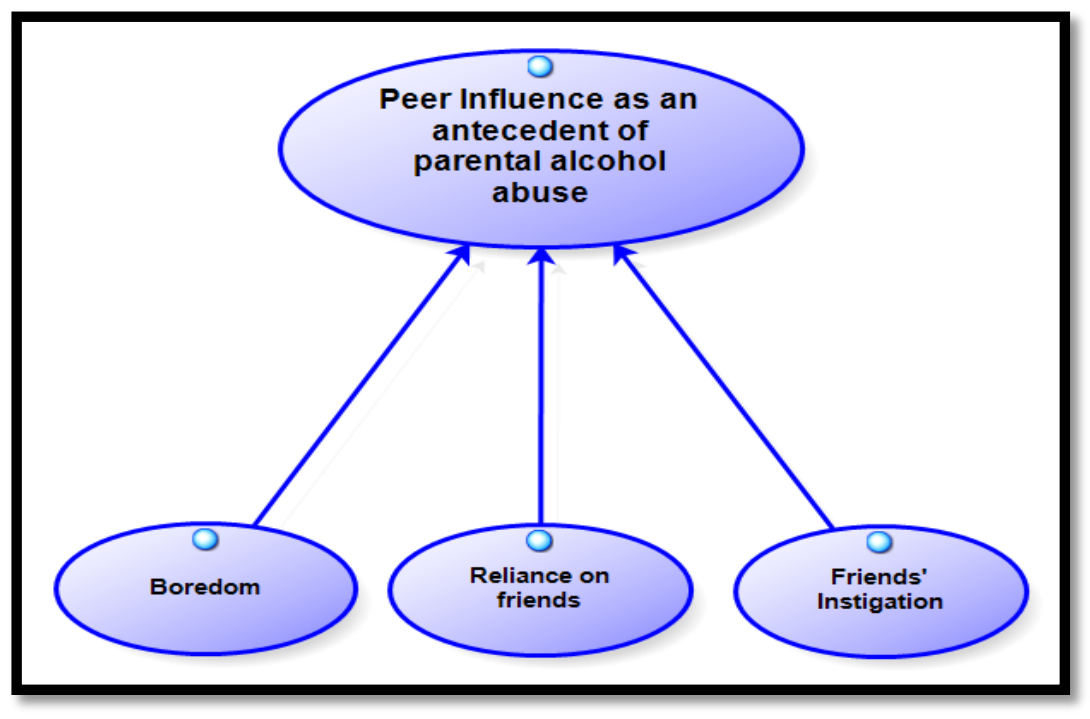

Figure 4: Peer Influence as Antecedent of Parental Alcohol Abuse 
Interestingly, the researcher found out from the perspective of the informants as indicated in figure 4 that relationship exists between peer influence and alcohol consumption in spite of the age of the parents. The participants perceived peer influence as an antecedent from three distinct ways. From the findings of the study, it was revealed that boredom was one of the single biggest predictor of alcohol abuse. Children of alcohol abuse parents (CAAF 7.7\%) revealed that their parents' alcohol abuse was as a result of frustration from boredom while parent $(\mathrm{P} 3.8 \%)$ made a self-disclosure that boredom was the reason for his alcohol abuse. Reliance on friends is another emerged perception explaining the antecedents of parents' alcohol abuse. Informants (CAAF 19.2\%) confirmed that their parents' alcohol abuse was as a result of closeness to friends. Correspondingly, most of the informants (CAAF 42.3\%) were of the opinion that friends' instigation was the reason for their parents' alcohol abuse. Corroborating the children's experience and submission, parents $(15.38 \%)$ revealed the impacts of friends' instigation.

\section{Discussion}

\section{Research Limitation}

The main limitation of this study is that all of the information derived was self-reported by the children of alcohol abuse parents who were all recruited through an NGO who is saddled with the responsibility of rehabilitating both the children and parents involved in alcohol abuse. Giving human nature, there is likelihood that these children were reporting only information necessary for stranger and putting up behaviors that was not true of their experiences or even over representing the incidents. Despite the fact that this possibility exists, the children were forthcoming to the satisfaction of the researcher. They described the antecedents of parents' alcohol abuse phenomenon.

Another limitation is that the paradigm model of the study is expected to disclose relationships among the differing aspects of the children experiences on parental alcohol abuse as opposed to propose a major association among the five components.

\section{Recommendation for Future Research}

The evidence in this study's report has highlighted extensive consequences of parental alcohol abuse. Therefore, the model generated from this study could guide further inquiries into areas of child impact including other hidden abuses, neglect, as well as other consequences, which can then inform specific protection and policy efforts.

One of the next steps stemming from this research is work on construct development to further define and develop the constructs in this study. Further testing of the model with a larger sample may reveal that more constructs should be included to refine the theory to provide a better understanding of the phenomenon. Constructs must be evaluated for how they will be operationalized and measured in order to test the theory from this research study. A scale can be developed based on the five categories of this study.

Another area for further study is more expanded theory testing. This exploratory study is an important first step. It provides more information regarding an understudied population. Closely linked to this and in view of the discovery of this study is the need for government to finance a national investigation that will provide the necessities of children of alcohol abusing parents.

Findings are based on the informants' perceptions concerning their experience from their parents' alcohol abuse as [9] emphasized that one of the fundamental features of qualitative research is that it focuses on informants point of views and it is not expected to be generalized to a wider populace. Seeing that there are various issues which have emerged in the current research, the likelihood for further and advanced explorations are enormous.

\section{References}

[1]. Abdu-Raheem, B. O. (2013). Sociological Factors to Alcohol Abuse and the Effects on Secondary School Students' Academic Performance in Ekiti and Ondo States, Nigeria. Contemporary Issues in Education Research, 6(2), 233-240.

[2]. Aina, O. F. \&Olorunsola, D. A. (2008). Alcohol and alcohol use portrayals in Nigerian video tapes: An analysis of 479 films and implications of public alcohol education. International Quarterly of Community Health Education, 28(1): 6371.

[3]. Akannam, T. (2008). North-West Rank Highest in Drug addiction. Nigerian Drug Statistics by Zone. Retrieved May 5, 2016.fromhttp://www.nairaland.com/203955/nigerian-drug-statistics-zone. 
[4]. Buddy, T. (2009). The difference between alcohol use abuse. Retrieved 25 March, 2016 from http://www.alcoholism.about.com/cs/alcohols/a/a9030425a.htm.

[5]. Chalder, M., Elgar, F. J. \& Bennett, P. (2006). 'Drinking and Motivations to Drink amongst Adolescent Children of Parents with Alcohol Problems', in Alcohol and Alcoholism; 41, 1, 107-113.

[6]. Chweya, M., \&Auya, S. (2014). Socio-economic effects of alcoholism on families in Mukuru slum, Nairobi County. International journal of innovation and scientific research, 9(1), 35-39.

[7]. Cleaver, H., Nicholson, D., Tarr, S. \& Cleaver, D. (2007). Child protection, domestic violence and parental alcohol misuse: Family experiences and effective practice. USA, Philadelphia: Jessica Kingsley Publishers.

[8]. Crawford, H. K., Leybourne, M. L., \& Arnott, A. (2000, January). How we ensured rigor from a multi-site, multidiscipline, multi-researcher study. In Forum Qualitative Sozialforschung/Forum: Qualitative Social Research (Vol. 1, No. 1).

[9]. Creswell, J. W. (1998). Quality inquiry and research design: Choosing among five traditions. Thousand Oaks.

[10].Creswell, J. W. (2007). Qualitative inquiry and research design: Choosing among five traditions (2nd ed.). Thousand Oaks, CA: Sage.

[11]. Gilchrist, G., \& Taylor, A. (2009). Drug-using mothers: Factors associated with retaining care of their children. Drug and alcohol review, 28(2), 175-185.

[12].Goliath, V., \& Pretorius, B. (2016). Peer risk and protective factors in adolescence: Implications for alcohol use prevention. Social Work, 52(1), 113-129.

[13]. Guba, E. G. (1981). Criteria for assessing the trustworthiness of naturalistic inquiries. ECTJ, 29(2), 75.

[14].Harry, B., Sturges, K. M., \&Klingner, J. K. (2005). Mapping the process: An exemplar of process and challenge in grounded theory analysis. Educational researcher, 34(2), 3-13.

[15].Igidi, T. (February 25, 2016). Few families are alcohol free in Nigeria. Daily Trust Newspaper.Retrieved February 27, 2016 from http://www.dailytrust.com.ng/news/home-front/-few-families-are-alcohol-free-in-nigeria/135355.html.

[16].Jeon, Y. H. (2004). The application of grounded theory and symbolic interactionism. Scandinavian journal of caring sciences, 18(3), 249-256.

[17].Kemjika, O. G., \&Ojiugo, A. B. (2015). Influence of family dysfunction on alcohol abuse of adolescent students of unity schools in south-south zone Nigeria. European Journal of Psychological Research Vol, 2(2).

[18].Kendler, K. S., Ohlsson, H., Sundquist, K., \&Sundquist, J. (2013). Within-family environmental transmission of alcohol abuse: a Swedish national study. JAMA psychiatry, 70(2), 235-242.

[19].Kirk, J., Miller, M. L., \& Miller, M. L. (1986). Reliability and validity in qualitative research (Vol. 1).Sage.

[20].Lincoln, Y. and Guba, E. (1985). Naturalistic Enquiry. Beverly Hills, CA: Sage.

[21].Lomborg, K., \&Kirkevold, M. (2003). Truth and validity in grounded theory-a reconsidered realist interpretation of the criteria: fit, work, relevance and modifiability. Nursing Philosophy, 4(3), 189-200.

[22]. Makanjuola, A. B., Daramola, O. \&Obembe, A. (2007). Psychoactive alcohol use among medical students in a Nigerian University: World psychiatry, 6(2): 112-114.

[23]. Mamman, H., Othman, A. T., \&Lian, L. H. (2014). Adolescent's and alcohols abuse in Nigeria. Journal of Biology, Agriculture and Healthcare, 4(1), 5-9.

[24].Maxwell, J. A. (1996). Qualitative research design (Vol. 41). Thousand Oaks, CA.

[25].Miles, M.B. \& Huberman, A. M. (1994). Qualitative Data Analysis, 2nd edn. Thousand Oaks, CA: Sage.

[26]. National Academy of Sciences (1996). Pathways of addiction: opportunities in alcohol abuse research. Washington, D.C.: National Academy Press.

[27].National Family and Parenting Institute and Alcohol Concern (2001).Putting the Children First: Helping Families to Deal with the Effects of Parent's Heavy Drinking on Family Life. London: A National Family and Parenting Institute and Alcohol Concern publication.

[28].Ogbebo, W. (2014). Need To Rid Nigeria Of Alcohol Abuse. Leadership Newspaper.Retrieved January 21, 2016 from http://leadership.ng/features/379049/need-rid-nigeria-alcohol-abuse.

[29]. Oshodi, O. Y., Aina, O. F., \&Onajole, A. T. (2010). Alcohol use among secondary school students in an urban setting in Nigeria: prevalence and associated factors. African journal of psychiatry, 13(1), $52-57$.

[30].Reid, J., Macchetto, P., \& Foster, S. (1999). No Safe Haven: Children of Alcohol-Abusing Parents. Center on Addiction and Alcohol Abuse at Columbia University.

[31].Reilly (1992).Impact of Alcohol Abuse on Families. Retrieved on April 14, 2016 from http://www.ncbi.nlm.nih.gov/books/NBK64258/.

[32].Richards, L. \& Richards, T. J. (1991). 'Computing in qualitative analysis: a healthy development?', Qualitative Health Research, 1 (2): 234-62.

[33].Sanni, K. B., Udoh, N. A., Okediji, A. A., Modo, F. N. and Eze, L. N. (2010). Family Types and Juvenile Delinquency Issues among Secondary School students in Akwa Ibom State, Nigeria Counselling Implications IN: Journal of Social Sciences 23(1): 21-28. NnamdiAzikiwe University, Akwa Nigeria.

[34].SAMHSA.(2009). Summary of findings from the 2008 National Household Survey on Alcohol Use and Health. Rockville, MD: SAMHSA.

[35].Seale, C. (1999). Quality in qualitative research. Qualitative inquiry, 5(4), 465-478.

[36].Strategy Unit (2004).Alcohol Harm Reduction Strategy for England. London: Strategy Unit. 
[37].Strauss, A., \& Corbin, J. (1990). Basics of qualitative research: Grounded theory procedures and techniques (1st ed.). Newbury Park, CA: Sage Publications.

[38].Strauss, A. L., \& Corbin, J. (1998). Basics of qualitative research: Techniques and procedures for developing grounded theory (2nd ed.). Thousand Oaks, CA: Sage.

[39].Corbin, J., \& Strauss, A. (2008). Basics of qualitative research: Techniques and procedures for developing grounded theory.

[40].Taylor, M. F., Coall, D., Marquis, R., \& Batten, R. (2016). Alcohol Addiction is a Scourge on the Earth and my Grandchildren are its Victims: the Tough Love and Resilient Growth Exhibited by Grandparents Raising the Children of Alcohol-Dependent Mothers. International Journal of Mental Health and Addiction, 1-15.

[41].Turning Point, (2016). Bottling it up the effects of alcohol misuse on children, parents and families.Retrieved 27 March, 2016 from http://www.alcoholsandalcohol.ie/6276/1/3499-3720.pdf.

[42]. Turning Point, (2006).Bottling it up: The effects of alcohol misuse on children, parents and families Retrieved on 12 May, 2016 from www.turning-point.co.uk/bottlingitup.

[43].Uwe, E. A. (2012). Pre-marital and marital therapy as family homeostasis and counselling strategy for enhancing societal security: in Keynote and lead presentations at the annual international conference of the counselling Association of Nigeria. Kolo I. A (ed). Pp 26-31.

[44].Wertz, F. J. (1986). The question of the reliability of psychological research. Journal of Phenomenological Psychology, 17(2), 181. 